\title{
Component Element Analysis of Stressed-skin Effect of Light Steel Structure
}

\author{
Zhifeng Zhang ${ }^{1, \text { a }}$, Zhe Zhang $^{2}$ \\ ${ }^{1}$ Shandong Polytechnic Jinan 250104, China \\ ${ }^{2}$ Centre for innovative Structures and Materials,School of Engineering,RMIT University,GPO Box \\ 2476, Melbourne 3001,Australia \\ a937090013@qq.com
}

\begin{abstract}
Keywords: Light steel structure; Stressed-skin effect; Component; Element analysis
Abstract. With the increasing advancement of industrialization, light steel has been used more and more frequently, hence stability and global stiffness of light steel structure has been received more and more attention. In order to find effective ways for enhancing connection strength and stiffness of light steel structure components, this paper gives an analysis of the force condition of light-steel plant under stressed-skin effect and the role of stressed-skin units in light steel structural component in such structure. Besides, this paper provides finite element analysis of the light steel structural components and probes into ways for simple design of light steel structure based on stressed-skin effect.
\end{abstract}

\section{Introduction}

Stressed skin is originated from ships and airplanes, referring to the thin-slab structure established by covering a thin metal plate over longitudinal and transverse ribs, which is of high stability, shearing strength and compressive property in a plane. In recent years, China has witnessed rapid development in light steel industry, and in plant roof and wall, light steel has been mainly used for manufacturing of stressed-skin retaining structure with different kinds of profiled steel sheets. However, the existing domestic studies on stressed-skin effect of light steel structure has failed to keep pace with the light steel industry in such rapid development. Therefore, it is necessary to intensify studies on stressed-skin effect of light steel structure.

1. Stressed-skin Effect and Force Analysis in Light-steel Plant

1.1 Stressed-skin effect

Stressed-skin structure is mainly composed of stressed-skin diaphragms, connectors and frame members, and works under the operating principles of connecting purlines and retaining plates, and various plates by different fasteners to form a series of shelves ribbed by the purlines. Such shelves are similar to deep web plates, that are of certain stiffness in the plane, and the purlines forming the stressed-skin structure are mainly used for reinforcement of the structure. Stressed-skin effect is formed jointly by the interaction between them. Stressed-skin can not only bear the load effects of various shelves in the plane but also transfer the shear force of the plates within the plane. Size of the effect is dependent on specific construction of the retaining plates in the stressed-skin structure[1]. According to the mechanism of formation of stressed-skin effect, fasteners must be used to fix the connection between purlines at four sides and the strength of connection between the frame members and plates shall be capable of baring the plate load within the plane and transferring the plate shear force. Main influences of application of stressed-skin effect in design of light steel structure are as shown in Table 1: 
Table 1 Main Influences of Stressed-skin Effect

Influence
(1)
Bescription connecting purlines and the stressed-skin diaphragms
through the skin, torsional deformation and lateral bending of the
purlines can be eliminated and shearing force can be transferred
to roof beams and joints.
By skinning treatment of the roof slabs, all plane steel units
can be built into an integral structure, which is good for reducing
later displacement of the components and increasing economic
benefits.
Stressed-skin diaphragms within the plane are of certain
(3)
stiffness and can impose lateral restriction on the purline flanges
and thus improve bearing capacity and stability of the purlines.

1.2 Force analysis of light-steel plant under stressed-skin effect

With the example of the light-steel plant with portal frame in a certain area, which is 65m in length, $6.2 \mathrm{~m}$ in column space and $9 \mathrm{~m}$ in cornice height, with windows occupying most of the space in walls, with imported BHP color steel sheets as roof slabs, purlines made of C200 $\times 75 \times 2.5 \times 2.0$ profile steel, and steel plates made of medium flange steel under average local wind pressure of $0.56 \mathrm{kN} / \mathrm{m} 2$. As the the owners required, the engineering cost and number of brace systems shall be reduced as much as possible[2] on the premise of proper integral stiffness and stability of the light-steel plant with portal frame.

In view of actual length of the plant, it is concluded that 3 column bracings should be erected. In order to meet the owners' requirements, the construction organization decided to carry out skinning treatment of the wall plates and roof slabs of the light-steel plant with the use of stressed-skin effect. The wall plates were designed into framed bent, no column bracing was erected and roof slabs, cornices and plant foundation were connected with each other. Fastening self-tapping screws were used for connection among purlines, roof slabs, and wall plates and connection among roof slabs and the screws were set with a distance less than $30 \mathrm{~cm}$. After analysis of transverse force on the wall plates and roof slabs in stressed-skin structure, it was concluded that, under transverse action, the wall plates were mainly under the shear force and extrusion force of the gable walls, and roof slabs were mainly under horizontal load. In addition, both wall plates and roof slabs were under horizontal wind load.

\section{Finite Analysis of Stressed-skin Elements in Light Steel Structural Components}

\subsection{Establishment of finite element model for stressed-skin units}

Elaboration on establishment of finite element model for stressed-skin elements was given with the example of stressed-skin units in walls. For the purpose of establishment of finite element model for wall structural skin in light-steel plant with portal frame, suitable kind of stressed-skin diaphragms should be chosen in light of the actual conditions of the plant project. In this case, V-840 profiled steel sheets were selected as walls. In order to simplify the model calculation process and ensure accuracy of the calculation results, the modeling process and profiled steel sheet conversion process shall be simplified in accordance with the principle of equal stiffness[3] .

Firstly, the finite element model for stressed-skin structure was established. It was assumed that the connection between purline and the plate, and connection among plates were rigid connection, when bending deflection, restriction and buckling of the stressed-skin diaphragms were ignored, finite element models for the framework components, connectors and bars were built. And then, element stiffness matrices for the bars, connectors and stressed-skin units were obtained, which were respectively as shown in the following: 


$$
\begin{aligned}
& {\left[K_{L}\right]^{e}\{\delta\}^{e}=\{F\}^{e} \quad[K]^{e}\{\delta\}^{e}=\{F\}^{e}} \\
& {[K]^{e}=\int_{-1}^{1} \int_{-1}^{1} \int_{-1}^{1}[B]^{T}[D][B][J] d \xi d \eta d \zeta}
\end{aligned}
$$

In stiffness matrix of the first two units, $\delta$ and $\mathrm{F}$ stand for nodal displacement vector of the structure and nodal force vector respectively. While, in the stiffness matrix of the stressed-skin units, matrix $\mathrm{B}, \mathrm{D}$ and $\mathrm{J}$ stand for the strain matrix, matrix determinant and essential matrix of the stressed-skin units. Elastic constant can be obtained by method of equal effects.

\subsection{Stiffness matrix of the whole structure}

The global stiffness matrix was obtained by integration processing of the element stiffness matrices for stress-skin bars, connectors and skins. In accordance with corresponding principles and methods, coordinates of element stiffness matrix for bars (KL), the skin and the connectors between stressed-skin diaphragms and plates were adjusted and converted to make them approach the global stiffness matrix. And after standard process transformation, those matrices were finally integrated into the global stiffness matrix[4]. It's worth noticing that, during the process integrating all element stiffness matrices into the global stiffness matrix, the connector were connected with the bar flanges at one end, and connected with shell element nodes at the other end, and the node of bars was cross-section shear center, in such case, if the nodes of bar elements and connector nodes failed to coincide with each other during coordinate transformation, the nodes would be off-center and overall discordance of the node displacement. Consequently, it was necessary to pay special attention to the connection between bars and stressed-skin elements to ensure successful completion of the process integrating element stiffness matrices into the global stiffness matrix. It was assumed that the element node $S$ was the host mode, connection point A between bars and connectors was the slave node, matrix KS was the element stiffness matrix for connectors at node S, matrix KA was the element stiffness matrix for connectors at point $\mathrm{A}, \delta \mathrm{S}$ and $\delta \mathrm{A}$ are respectively the displacement vectors of the host and slave nodes, thus, the relationship equation of displacement vector of the host and slave nodes can be established by node offset correction matrix T. Given that there is only one slave node for a certain connection element node, the element stiffness matrix for connectors at the slave nodes represented by $\mathrm{T}$ and KA could be established with relevant principles. On such basis, after transformation of necessary coordinates, the final global stiffness matrix is obtained, of which the equation expression is given as follows:

$$
[K]\{\delta\}=[F]
$$

Wherein, $\mathrm{K}, \delta$, and $\mathrm{F}$ respectively stands for global stiffness matrix, nodal displacement vector and nodal force vector.

2.3 Establishment of finite element model for wall skin

Given that the wall is built with the V-840 profiled sheet, which is still slab in down-wave direction, thus it can be seen that the physical constants of the model in this direction remain the same. Constant parameters and other parameters obtained under the same constant parameters and shear effect of stressed-skin steel frame are as shown in Table 2[5].

\begin{tabular}{|c|c|c|c|}
\hline \multicolumn{4}{|c|}{ Main Input Parameters of V-840 Profiled Steel Sheet } \\
\hline $\mathrm{E}=\mathrm{Ex}$ & Ey & G & $\mu x$ \\
\hline $2.06 \times 105$ & $8.83 \times 105$ & $7.9 \times 104$ & 0.30 .07 \\
\hline \multicolumn{4}{|c|}{ Shear Effect Parameters of Stressed-skin Diaphragms with Portal Frame } \\
\hline Shear capacity & Shear stiffness & $\begin{array}{l}\text { Allowable value } \\
\text { of wind load }\end{array}$ & $\begin{array}{l}\text { Allowable value } \\
\text { of earthquake load }\end{array}$ \\
\hline $5.103 \mathrm{kN} \cdot \mathrm{mm}-1$ & $2365 \mathrm{~N} \cdot \mathrm{mm}-1$ & $2.14 \mathrm{kN} \cdot \mathrm{mm}-1$ & $2.00 \mathrm{kN} \cdot \mathrm{mm}-1$ \\
\hline
\end{tabular}

Table 2 Main Input Parameters and Parameters of Stressed-kin Diaphragms in Finite Element Model for V-840 Profiled Sheet Wall

Remarks: Unit of parameter of profiled sheet is $\mathrm{N} / \mathrm{mm} 2$. 
According to analysis of the above parameters, it is proved that for establishment of finite element model for walls in light steel plant, orthotropic four-node linear elasticity shell elements can be used as stressed-skin diaphragms, three-dimensional linear finite strain beam element supplied by ANSYS can be used as steel frame, and connection between plates can be realized by way of coupling. In the model, distance between beams of the infinite element test model in the wall skin elements is $4.3 \mathrm{~m}$, the length of top and bottom components is $4.5 \mathrm{~m}$, and connection distance of profiled sheet and stressed-skin diaphragms and components is $30 \mathrm{~cm}$ and $28 \mathrm{~cm}$ respectively. In addition, connection between purlines and steel structural members is realized by hinged joints, The modeling is carried out via ANSYS.

\section{Ways of Simple Design of Light Steel Structure with Portal Frame based on Stressed-skin Effect}

A comparison of the displacement produced by different horizontal loads of stressed-skin light steel structure and pure frame structure is made with the use of above finite element model, the comparison results are as shown in Table 3. According to such results, it is concluded that simple design light steel structure with portal frame can be realized by appropriate selection of structural steel and fasteners and further simplification in light of node characteristics of the structure.

Table 3 Comparison on Horizontal Load Displacement of Stressed-skin Structure and Pure Frame Structure

\begin{tabular}{cccc}
\hline $\begin{array}{c}\text { Form of Light } \\
\text { Steel Structure }\end{array}$ & \multicolumn{3}{c}{ Horizontal Load Value/KN } \\
\hline & 10 & 30 & 50 \\
Stressed-skin & 0.349 & 1.048 & 1.752 \\
Structure & & & 161.794 \\
$\begin{array}{l}\text { Pure Frame } \\
\text { Structure }\end{array}$ & 32.347 & 97.036 & \\
\hline
\end{tabular}

\section{Conclusion}

By finite element modeling analysis of the stressed-skin effect and stressed-skin elements in walls of light-steel plant with profiled steel frame, it is concluded that, it can effectively improve the global stiffness of the light steel structure, reinforce the connection strength between plates, purlines and plates and provide lateral restriction of the components connected and reduce nodal displacement of the structure by skinning treatment of the steel structural components with the use of stressed-skin effect in light steel structural component elements. Thus, it plays an important role in manufacturing, development and application of light steel structure.

\section{Acknowledgements}

This work was supported by Shandong Science and technology project:Study on design method of door type rigid frame "skin unit"(No.J15LG51) .

\section{References}

[1]Pan L C, Wang X Y, Wang D F. Influence of Stressed Skin Effect on the Bearing Capacity of Electrostatic Precipitator Casing Wall[J]. Advanced Materials Research, 2014, 1049-1050:246-250.

[2]Wrzesien A M, Lim J B P, Xu Y, et al. Effect of stressed skin action on the behaviour of cold-formed steel portal frames[J]. Engineering Structures, 2015, 105:123-136. 
[3]Cao Z, Du P, Chen Z, et al. The stability and stressed skin effect analyses of an $80 \mathrm{~m}$ diameter single-layer latticed dome with bolt-ball joints[J]. International Journal of Steel Structures, 2016, 16(2):279-288.

[4]Wrzesien A M, Phan D T, Lim J B P, et al. Effect of stressed-skin action on optimal design of cold-formed steel square and rectangular-shaped portal frame buildings[J]. International Journal of Steel Structures, 2016, 16(2):299-307.

[5]Guardiola F A, Dioguardi M, Parisi M G, et al. Evaluation of waterborne exposure to heavy metals in innate immune defences present on skin mucus of gilthead seabream ( Sparus aurata )[J]. Fish \& Shellfish Immunology, 2015, 45(1):112-123. 